\title{
Estimation and repeatability of the response to inhaled histamine in a community survey
}

\author{
S CHINN, J R BRITTON, P G J BURNEY, A E TATTERSFIELD, \\ A O PAPACOSTA
}

From the Department of Community Medicine, United Medical and Dental Schools, St Thomas's Campus, London; and the Respiratory Medicine Unit, City Hospital, Nottingham

ABSTRACT Epidemiological problems arising from the absence of an agreed definition of asthma have led to the use of bronchial reactivity tests in community surveys of asthma prevalence. Since only a minority of the general population will develop bronchoconstriction in response to the dose of histamine considered acceptable for use in the community it is important to make maximum use of the data available. Several methods for summarising the information in the dose-response curve obtained from a histamine challenge test have been compared. A standardised histamine challenge test was administered to 797 subjects selected from two communities, and a repeat test to 106 subjects. The test was well accepted. For most subjects FEV $_{1}$ rose initially after administration of histamine (median rise $100 \mathrm{ml}$ ), so maximum $\mathrm{FEV}_{1}$ was used as the baseline from which the $20 \%$ fall to achieve a $\mathrm{PD}_{20}$ was calculated. In order to use all the data rather than just two points on the FEV 1 -log dose graph, $\mathrm{PD}_{20}$ was estimated by means of curve fitting, and the values were compared with $\mathrm{PD}_{20}$ from linear interpolation. An exponential curve was found to fit the data well. Extrapolation from the maximum dose of $4 \mu \mathrm{mol}$ up to $8 \mu \mathrm{mol}$ was allowed in the estimation of PD $_{20}$ by both methods. The curve fitting method gave slightly more reproducible $\mathrm{PD}_{20}$ values than did linear interpolation, and also gave more estimates in the range $0.03-8 \mu \mathrm{mol}$. The repeatability of $\mathrm{PD}_{20}$ compared well with that of asthmatic subjects tested in a clinical environment. Curve fitting has an advantage over linear interpolation in large community studies, for which analysis of data by computer is essential.

\section{Introduction}

Most patients with asthma show bronchial hyperreactivity to a variety of non-allergenic stimuli, ${ }^{1}$ although the precise relationship between reactivity and asthma is still debated. In general, hyperreactivity is related to the severity of asthma, as judged by symptoms, ${ }^{2}$ requirement for treatment, ${ }^{3}$ and diurnal variation in peak expiratory flow. ${ }^{4}$ Various guidelines have recently been suggested for the standardisation of bronchial challenge tests. ${ }^{56}$

The epidemiological problems arising from the absence of any agreed definition of asthma have led to interest in the possibility of using tests of bronchial reactivity in community surveys. In this situation the test needs to be quick and simple and be acceptable to

Address for reprint requests: Miss S Chinn, Department of Community Medicine, St Thomas's Hospital Medical School, London SE1 7EH.

Accepted 6 October 1986 the general population, and to give reproducible results under field conditions. It is essential to have a standardised protocol to be used for all subjects. Yan et $a l^{6}$ have developed a method for this purpose, giving increasing concentrations of histamine from hand held deVilbiss nebulisers and measuring the response as the dose of histamine estimated by interpolation to cause a $20 \%$ fall $\left(\mathrm{PD}_{20}\right)$ in one second forced expiratory volume $\left(\mathrm{FEV}_{1}\right)$. In a pilot study Britton et al $^{7}$ showed Yan's method to be quicker and at least as reproducible as two alternative tests, and this was therefore the method chosen for the community survey.

Measurement of bronchial reactivity in epidemiological studies is subject to certain restraints. Few of the population will have had any previous experience of forced expiratory manoeuvres. Since the general population may be less tolerant of side effects than subjects in the laboratory, the maximum dose of histamine that can be given is lower, and a smaller proportion of subjects will have a $\mathbf{P D}_{20}$ that can be esti- 
mated. Hence it is important to obtain the maximum information from the data that are obtained.

In the main study Yan's method of histamine challenge was used to measure $P_{20}$ in 797 subjects as part of a community survey of asthma prevalence in two areas of southern England. ${ }^{8}$ Repeat studies were performed in 106 subjects 1-14 days after the first test. In the study reported in this paper we set out to establish the best way to analyse histamine challenge doseresponse data obtained in an epidemiological setting by determining: (1) the proportion of subjects for whom a $\mathrm{PD}_{20}$ value was obtained by fitting doseresponse curves compared with the use of linear interpolation; (2) the repeatability of $\mathrm{PD}_{20}$ values for the two methods; (3) whether $\mathbf{P D}_{20}$ should be estimated as a $20 \%$ fall from the post-saline $\mathrm{FEV}_{1}$ or the maximum $\mathrm{FEV}_{1}$.

$P_{10}$ was estimated and assessed in the same way as $\mathbf{P D}_{20}$. The fact that more subjects would have a $\mathrm{PD}_{10}$ than a $\mathrm{PD}_{20}$ value of $\leqslant 8 \mu \mathrm{mol}$ could favour the use of $P D_{10}$ in a community survey if the results are as repeatable.

\section{Methods}

\section{SUBJECTS}

A questionnaire about symptoms of asthma was administered to all subjects aged 18-64 years in two villages in Hampshire and a market town in Dorset as part of a study of asthma prevalence. After completion of the questionnaire 1325 subjects were asked to attend for a histamine challenge test at their general practitioner's surgery or health clinic. The subjects consisted of two groups, a $20 \%$ random sample (855) of the 4277 subjects aged 18-64 years who returned a completed questionnaire and all remaining subjects (470) who answered "Yes" to the question "Have you had wheezing or whistling in your chest at any time in the last 12 months?" In this paper no distinction is made between the two groups of subjects; the prevalence of hyperreactivity and its relation to smoking history and skin sensitivity as estimated from the random sample has been reported ${ }^{8}$ and the relation of hyperreactivity to associated symptoms will be reported later.

Subjects who had taken theophyllines or antihistamines in the previous 24 hours or a bronchodilator in the last six hours were asked to return later after omitting this treatment. Ethical approval was obtained from the local ethical committees and all subjects had the test explained and signed a consent form before the test was carried out.

A total of 170 subjects were invited to return for a second histamine challenge test. These consisted of a $10 \%$ random sample of all subjects in one area and in addition all subjects whose $\mathrm{FEV}_{1}$ had fallen by $20 \%$ in the initial test in both areas, plus a few subjects whose fall in $\mathrm{FEV}_{1}$ approached $20 \%$. The decision to $\stackrel{?}{?}$ adminster the second test by the same or a different person was taken at random.

\section{MEASUREMENTS}

Height was measured and predicted $\mathrm{FEV}_{1}$ calculated as recommended by Cotes et al. ${ }^{9} \mathrm{FEV}_{1}$ and forced vital capacity were measured with a dry spirometer (Vitalograph, Buckingham, England). Initial FEV ${ }_{1} \overrightarrow{\vec{\omega}}$ was recorded as the maximum of three consecutive $\stackrel{\circ}{\circ}$ measurements that agreed to within $5 \%$. Subjects $\overrightarrow{\vec{x}}$ whose initial $\mathrm{FEV}_{1}$ was less than $60 \%$ of the predicted value were not challenged with histamine.

Other details of the histamine challenge test were as described by Yan et al, ${ }^{6}$ with doubling doses of from 0 0.03 to $4 \mu \mathrm{mol}$ administered to subjects with a history of wheezing or whose post-saline $\mathrm{FEV}_{1}$ was less than $\vec{c}$ $90 \%$ predicted. All other subjects were given $0.06 \mu \mathrm{mol}$ histamine followed by quadrupling doses of histamine until their $\mathrm{FEV}_{1}$ had fallen by at least $10 \%$, when the challenge regimen was changed to the slower $\vec{\varphi}$ schedule. The test was stopped when the $\mathrm{FEV}_{1}$ had fallen by $20 \%$ or more from the post-saline value or the $4.0 \mu \mathrm{mol}$ dose had been given, or at the subject's request.

ESTIMATION OF PD $_{20}$

$\mathrm{PD}_{20} \mathrm{FEV}_{1}$ was estimated by linear interpolation on the basis of data from the last two doses administered, ${ }^{10}$ with extrapolation to one doubling dose $\frac{3}{5}$ $(8 \mu \mathrm{mol})$ beyond the maximum administered, following Cockcroft et al. ${ }^{11} \mathrm{PD}_{20}$ was estimated by using all the available data and fitting the exponential curve

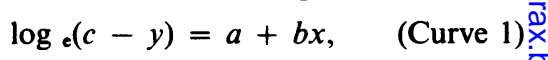

where $y$ is $\mathrm{FEV}_{1}, x$ is $\log _{10}$ (dose), $c$ represents mean $\mathrm{FEV}_{1}$ before it is affected by histamine, $b$ is a "slope" parameter, and $a$ is a curve position parameter. Since Woolcock et al ${ }^{12}$ fitted a logistic curve, we also fitted $\mathrm{O}$

$$
\log _{e}(c-y) / y=a+b x . \quad \text { (Curve 2) }
$$

Extrapolation to a dose of $8 \mu \mathrm{mol}$ was allowed for both curves as with the linear interpolation method. $N$ Curves were fitted provided that two or more doses of $N$ histamine were administered-that is, they were fitted to all sets of data for which $\mathbf{P D}_{20}$ values were obtained ${ }^{\omega}$ by linear interpolation. When only two doses of histamine were given the post-saline $\mathrm{FEV}_{1}$ was used as the estimate of $c$. Details are given in the appendix.

Most subjects showed a small increase in FEV $_{1}^{+}$ after the low dose of histamine, so we also calculated $\frac{0}{0}$ the estimates described above as the dose producing a $20 \%$ fall from maximum $\mathrm{FEV}_{1}$. Linear interpolation $\frac{\mathrm{P}}{\mathbb{D}}$ uses the doses either side of the estimate. Occasionally을 both the last two doses administered produced a 


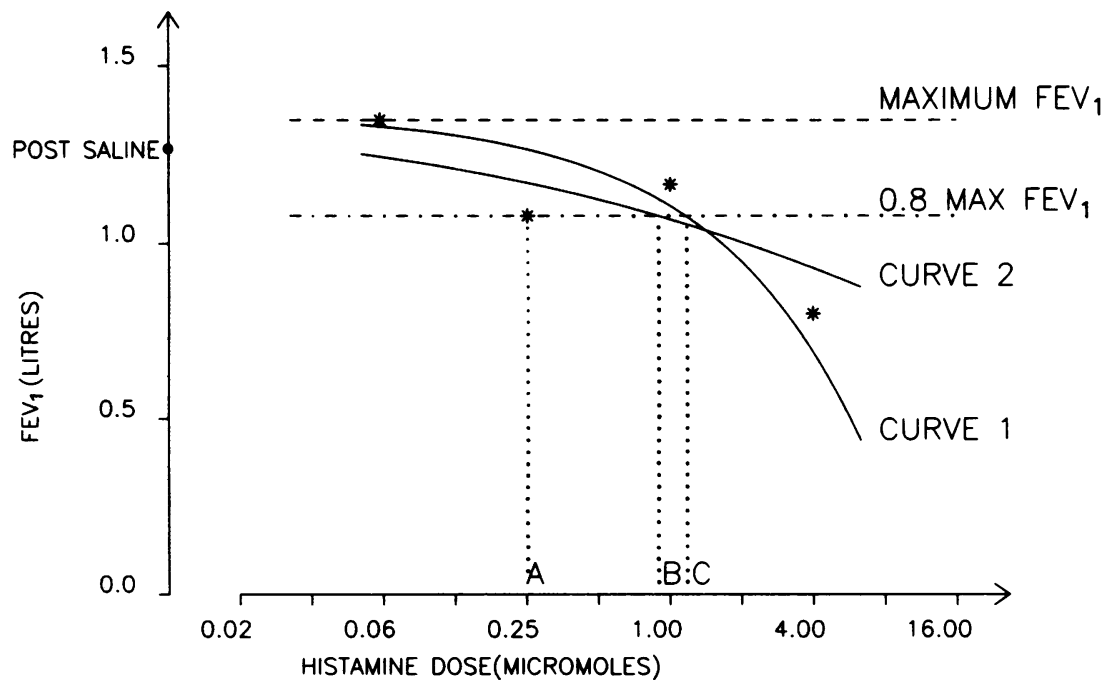

Fig 1 Curves fitted to data for a subject showing more variability in FEV 1 than the average, illustrating the desirability of using all the data rather than just two points. The post-saline $F E V_{1}(O)$ and $F E V_{1}\left({ }^{*}\right)$ after doses 0.06, 0.25, 1.0, and 4.0 umol histamine are shown. The line ----- denotes maximum $F E V_{1}$ and --.--_- $80 \%$ of maximum $F E V_{1}$. The histamine dose causing a $20 \%$ fall in FEV $\left(P D_{20}\right)$ is estimated as $A: 0 \cdot 25$ (linear interpolation); B: 0.89 (curve 2); and C: $1 \cdot 17 \mu \mathrm{mol}$ (curve 1).

greater than a $20 \%$ fall from maximum $\mathrm{FEV}_{1}$ and in this case the two appropriate earlier doses were used for the estimate. This corresponds to the procedure that would be followed if the test were terminated when a $20 \%$ fall from maximum FEV $_{1}$ was reached. An example of each curve fitted to data for one subject is shown in figure 1 , for whom the second administered dose of histamine produced a $20 \%$ fall from $\mathrm{FEV}_{1}$ maximum.

The methods of estimating $\mathbf{P D}_{\mathbf{2 0}}$ were compared according to the number of subjects who achieved a $\mathrm{PD}_{20}$ and the repeatability of the measurements.

$\mathrm{PD}_{10}$ was estimated, by linear interpolation and from the same curves, in a similar way to $P_{20}$.

\section{REPEATA BILITY}

The mean and standard deviation of the difference between the estimates of $\mathrm{PD}_{20}$ for repeat tests were calculated for the subjects tested twice. Repeatability was also calculated for $\mathrm{PD}_{10}$, post-saline $F E V_{1}$, and maximum $F_{E V}$. The within subject standard deviation was calculated by dividing the standard deviation of the difference of two repeat estimates by the square root of $2 .{ }^{13} \mathrm{~A}$ dimensionless measure of repeatability, intraclass correlation coefficient, ${ }^{14}$ was also calculated.

\section{Results}

Of 1325 subjects invited to undergo a histamine chal- lenge test, $834(63 \%)$ agreed. Thirty seven subjects were not given histamine, four owing to difficulty in complying with instructions and 33 because the initial or post-saline $\mathrm{FEV}_{1}$ was less than $60 \%$ predicted. Thus 797 subjects were given at least one dose of histamine at the first test, including four subjects with an initial $\mathrm{FEV}_{1}$ less than $60 \%$ predicted who were given histamine in error; of these, $512(64.2 \%)$ were randomly selected.

Most subjects (74.4\%) increased their $\mathrm{FEV}_{1}$ after the post-saline measurement, $83(10.4 \%)$ having their maximum recorded $\mathrm{FEV}_{1}$ after the final $4 \mu \mathrm{mol}$ dose of histamine. The increase in $\mathrm{FEV}_{1}$ over the postsaline $\mathrm{FEV}_{1}$ ranged up to 0.9 litre in absolute terms (a $30 \%$ increase), although the median increase was only $100 \mathrm{ml}$.

Four subjects were given just one dose of histamine, of whom three had a $20 \%$ fall in $\mathrm{FEV}_{1}$ after that dose and so did not have a $\mathrm{PD}_{20}$ that could be estimated. Each method of estimation of $\mathrm{PD}_{20}$ was applied to the data for the remaining 793 subjects. The residual standard deviation about the curves was less than 0.21 for $88.1 \%$ of subjects for curve 1 and $86.0 \%$ for curve 2 ; the mean residual standard deviation was 0.151 for each curve. The larger residual standard deviations were found to be due to random variation in the FEV rather than systematic deviations from the fitted curves. This is illustrated in the example in figure 1 , where the residual standard deviations about the curves were 0.23 and 0.211 . 
NUMBERS OF SUBJECTS WITH PD 10 AND PD $_{20}$ VALUES

The number of estimates of $\mathbf{P D}_{20}$ is shown in table 1 , and varies according to method from $20 \cdot 2 \%$ to $26 \cdot 2 \%$ of the 793 subjects. Curve fitting produced more estimates in the range $0.03-8 \mu \mathrm{mol}$ than did linear interpolation, the difference being between 28 and 38 subjects. Use of the maximum $\mathrm{FEV}_{1}$ as baseline rather than the post-saline $\mathrm{FEV}_{1}$ increased the number of estimates, since a $20 \%$ fall was achieved at greater absolute $\mathrm{FEV}_{1}$. The numbers achieving a $20 \%$ fall from the maximum $\mathrm{FEV}_{1}$, when calculated by linear interpolation and by fitting curves 1 and 2, were 173, 208 , and 201 respectively, whereas the corresponding numbers achieving a $10 \%$ fall were 292,324 , and 319 , about $50 \%$ more.

\section{REPEAT A BILITY}

A total of $112(66 \%)$ of the 170 subjects invited presented for retest. These included $19(48 \%)$ of the 40 randomly selected subjects and $93(72 \%)$ of the 130 who had a fall of $20 \%$, or nearly $20 \%$, in FEV 1 at the first test. Six subjects were not given histamine on the second occasion, five because of recurrent wheezing after the first test, and one because of error in calculating the initial $\mathrm{FEV}_{1}$ as being less than $60 \%$ predicted. Two subjects had a $20 \%$ fall in $\mathrm{FEV}_{1}$ after one dose of histamine, so that a second $\mathrm{PD}_{20}$ could not be $\stackrel{\times}{\mathrm{x}}$ estimated. Duplicate estimates of $\mathrm{PD}_{20}$ were therefore available in 104 subjects.

The repeatability of $\log \mathrm{PD}_{20}$ values obtained by $\frac{\mathrm{C}}{\sigma}$ each method is given in table 2 as the standard devi- $\overline{\bar{c}}$ ation of the differences between test and retest values. $\frac{\nabla}{\mathscr{Q}}$ This is given for all 104 subjects, for the 90 subjects with at least one estimate less than or equal to $8 \mu \mathrm{mol}$, 2 and for the 64 subjects with all estimates less than $\overrightarrow{0}$ $8 \mu \mathrm{mol} . \mathrm{PD}_{20}$ values estimated by curve fitting were a $\overrightarrow{\vec{\omega}}$ little more repeatable (had a smaller standard deviation) than those for linear interpolation, and $\mathrm{PD}_{20}$ values from curve 1 were slightly more repeatable than those from curve 2 (columns one and two). The ! repeatability of the three methods was similar when restricted to the 64 subjects with no estimate greater of than $8 \mu \mathrm{mol}$. The number with a $\mathrm{PD}_{20}$ of $8 \mu \mathrm{mol}$ or 윽 less on both occasions varied from 68 for linear inter- polation, with post-saline $\mathrm{FEV}_{1}$ as baseline, to 73 for curve 1. Figure 2 shows the relation between curve $1 \stackrel{\text { C }}{2}$ $\mathrm{PD}_{20}$ for the second test to that for the first, on the basis of fall from maximum $\mathrm{FEV}_{1}$. The choice of $\overrightarrow{\vec{\theta}}$ baseline had little influence on the repeatability of the estimated $\mathrm{PD}_{20}$.

The post-saline $\mathrm{FEV}_{1}$ was slightly less repeatable than maximum FEV . Table 3 also shows the repeatability of $\mathrm{PD}_{10}$ estimates from curve 1, with $\mathrm{FEV}_{1}$

Table 1 Numbers of censored and estimated $P D_{20}$ values obtained by methods of linear interpolation and curve fitting for the 793 subjects given at least two doses of histamine

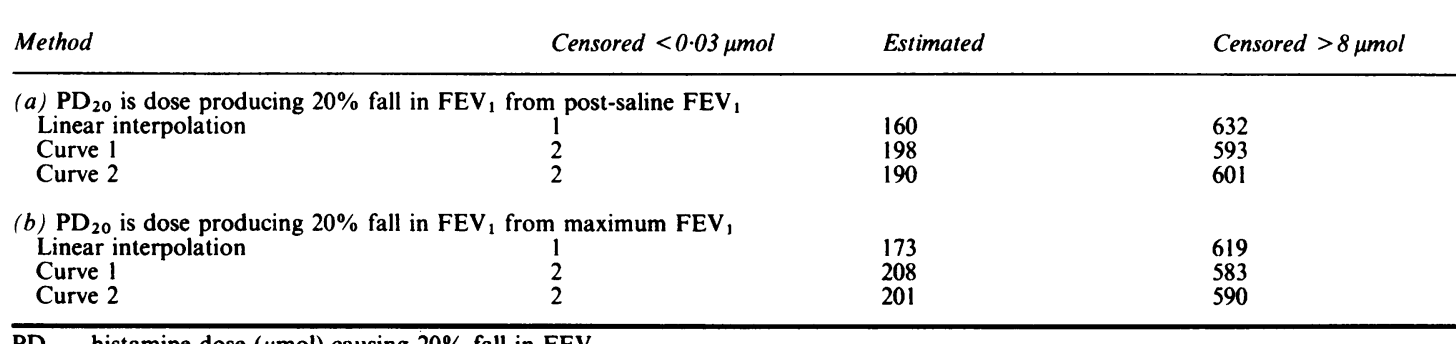

$\mathrm{PD}_{20}$-histamine dose $(\mu \mathrm{mol})$ causing $20 \%$ fall in $\mathrm{FEV}_{1}$.

Table 2 Repeatability of $\log _{10} P D_{20}$ (values greater than $\log 8$ set to $\log 8$ where appropriate)

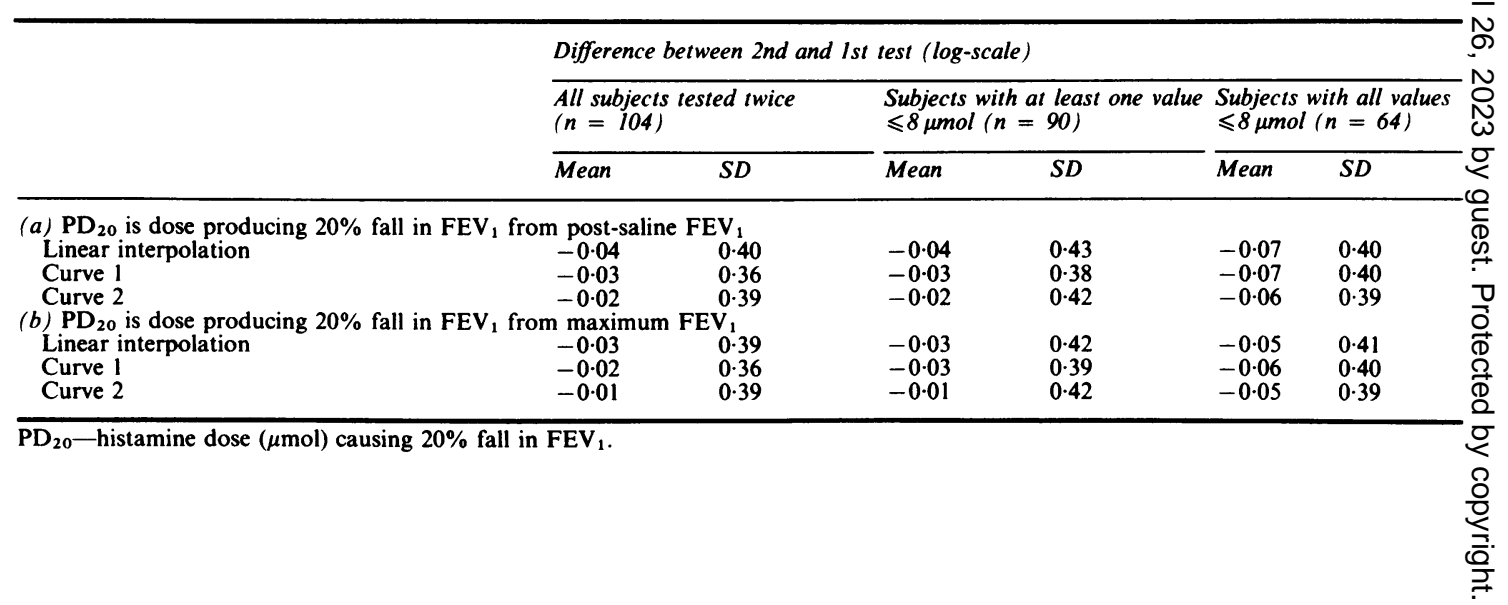


Table 3 Repeatability of FEV 1 and curve parameters

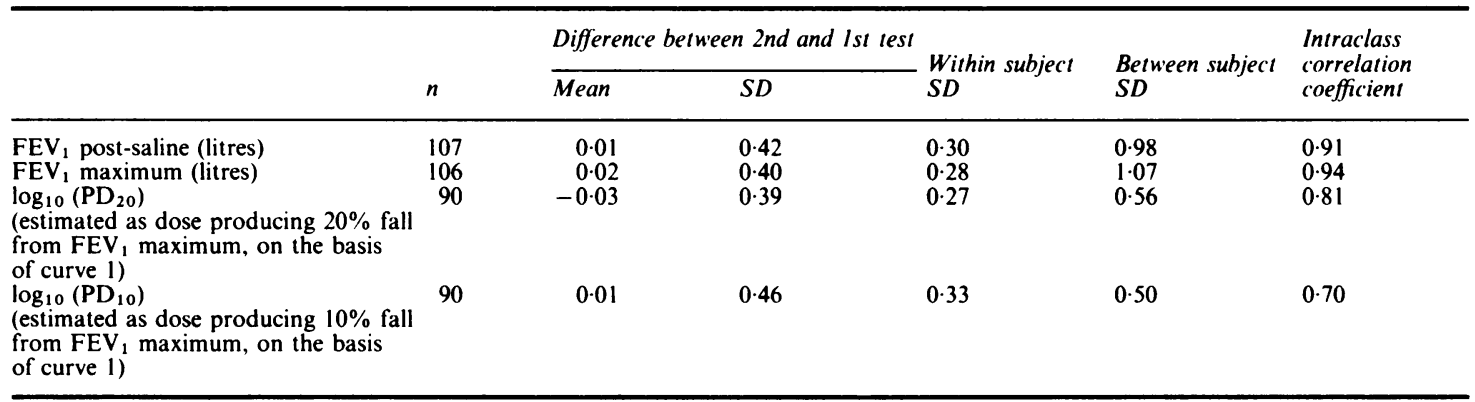

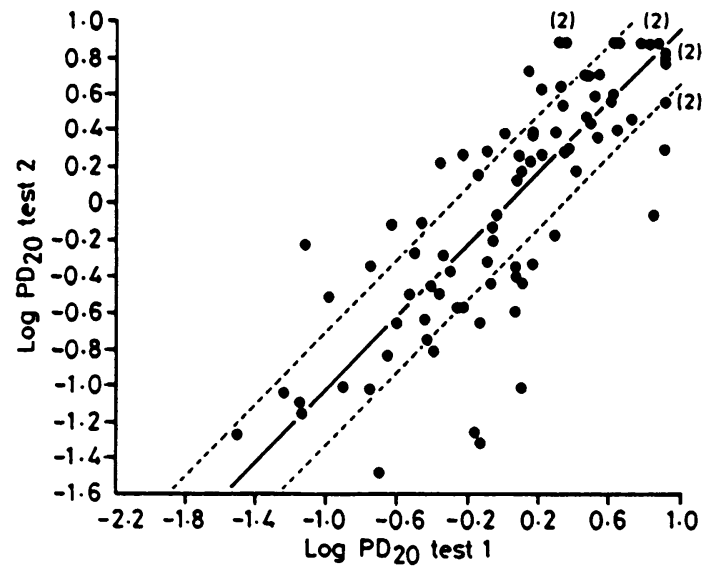

Fig 2 Relation between (log) $P D_{20}$ (histamine dose ( $\mu \mathrm{mol}$ ) causing $20 \%$ fall in FEV $V_{1}$ ) at the second test to (log) $P D_{20}$ at the first test, as estimated from curve 1 with maximum FEV $V_{1}$ as baseline. The line - is the line of identity and the lines - - - denote a difference of one doubling dose of histamine.

maximum as baseline, compared with that of $\mathrm{PD}_{20}$ in the same 90 subjects, whose data are given in column 2 of table 2 . The intraclass correlation coefficient was less than that for $\mathbf{P D}_{20}$ in these subjects. Estimates of repeatability of $P D_{10}$ from curve 2 , and estimates based on post-saline $F E V_{1}$, were similar. PD $_{10}$ estimated by linear interpolation was less repeatable, the difference in repeatability being similar to that of $\mathrm{PD}_{20}$ (data available but not shown).

Repeatability was affected to a small extent by differences in time of day of measurement, the time between tests (range 1-14 days), and the person performing the test. Data were available for the 27 subjects retested one day later, at the same time of day to within one hour, and by the same tester. If we excluded two subjects with a $\mathbf{P D}_{\mathbf{2 0}}$ greater than $8 \mu \mathrm{mol}$ on both occasions, the within subject standard deviation of curve $1 \mathrm{PD}_{20}$ was reduced from 0.27 (table 3) to $0 \cdot 18$.

\section{Discussion}

Studies on asthma prevalence have been greatly hampered by the absence of an agreed definition of asthma. Measurement of bronchial responsiveness provides an objective test, and since it is an important marker of asthma there has been interest recently in exploring the role of bronchial reactivity measurement in the assessment of asthma prevalence in the community.

Measurement of bronchial reactivity in large surveys poses different problems from measurements in the laboratory. The incidence of side effects considered acceptable in a community may be lower than for subjects in the laboratory, so a lower maximum dose of histamine has to be given. We found in a pilot study that the test described by Yan $e^{a} \mathrm{l}^{6}$ was feasible in inexperienced subjects and that $4 \mu \mathrm{mol}$ histamine was the highest dose that was generally well tolerated. With this low maximum dose of histamine fewer subjects will develop bronchoconstriction, so it is important to estimate the response by a method that makes maximum use of the information available.

$\mathrm{PD}_{20}$ values have usually been obtained by linear interpolation between the response to the last two doses of histamine, with extrapolation up to one further doubling concentration of histamine by some workers. ${ }^{411}$ This technique is simple and gives an immediate answer. Fitting a curve to the data is more complicated but, when the data are of necessity analysed by computer, curve fitting is no more difficult than linear interpolation. Since we needed to analyse a large number of histamine dose-response curves we decided to compare the linear interpolation method with two curve fitting models, extrapolating up to one doubling dose $(8 \mu \mathrm{mol})$ for each method to increase the number of estimates. We did not include in this comparison estimates of $\mathrm{PD}_{20}$ if only one dose of histamine was given, as the published method of estimation requires linear interpolation between postsaline $F E V_{1}$ and post-histamine $F V_{1}$ at the first dose on a linear scale $e^{10}$ and is inappropriate when linear 
interpolation is otherwise carried out on a log-dose scale (post-saline "dose" $=0$, and $\log (0)=-\infty$ ).

We looked at two curves, both of which are described by the minimum three parameters, upper asymptote, slope, and position. Both curves appear to be preferable to the quadratic equation recommended by Neijen' ${ }^{15}$ which is less flexible in shape and has no slope parameter. Curve 1 was the simplest such curve. Curve 2 was chosen because Woolcock et al ${ }^{12}$ had fitted a logistic curve to their data. The repeatability of $\mathrm{PD}_{20}$ values from curve 2 was less good than that of values from curve 1 .

On the basis of fall from maximum $\mathrm{FEV}_{1}$, a $\mathrm{PD}_{20}$ value was obtained in 173 subjects by the linear interpolation method. Curve fitting increased the number of subjects with an estimated $\mathrm{PD}_{20}$ value by 35 and 28 subjects respectively for curves 1 and 2 . The lower number from linear interpolation occurred in part because an extrapolated value was obtained only if the $\mathrm{FEV}_{1}$ after the final dose was less than the previous $\mathrm{FEV}_{1}$, whereas curve fitting provided an estimate whether or not this was the case. In the subjects tested twice there were correspondingly more estimates by curve fitting than by linear interpolation, which led to more subjects with one or both estimates less than $8 \mu \mathrm{mol}$. The repeatability of $\mathrm{PD}_{20}$ values obtained by fitting curve 1 was better than that of values obtained by linear interpolation, as shown by column 2 of table 2. Column 3, which contains results only for subjects with all estimates less than $8 \mu \mathrm{mol}$, apparently shows greater repeatability for linear interpolation and curve 2 estimates than does column 2 and lower repeatability for curve 1 estimates. This is because some of the subjects who are included in column 2 but not in column 3 had much more discrepant values derived from linear interpolation and curve 2 than from curve 1 , and column 3 is included only to demonstrate this point. Selective exclusion of subjects with values above $8 \mu \mathrm{mol}$ for each method would be even more misleading as different subjects would be included for each method.

With any measurement having an upper limit above which values cannot be obtained there is no ideal solution to the problem of estimating repeatability. Methods can be properly compared only when carried out on the same or comparable subjects, and even then care must be taken not to exclude subjects more variable by one method than another. There is also the problem of whether the between subject variation used in the calculation of the intraclass correlation coefficient should be estimated from subjects tested twice or from a sample more representative of the population. $\mathbf{P D}_{10}$ had a greater within subject variation and greater between subject variation than $P_{20}$ in the 90 subjects; the intraclass correlation coefficient showed $\mathrm{PD}_{10}$ to be relatively less repeatable than
$\mathrm{PD}_{20}$. Judged against variation in all 793 subjects studied, $\mathrm{PD}_{10}$ and $\mathrm{PD}_{20}$ had similar repeatability. We have preferred to use $\mathrm{PD}_{20}$ since this has been usedo more often by others.

Other measures of reactivity that have been used $\frac{\overline{\bar{F}}}{\overline{5}}$

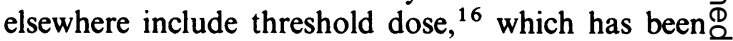
shown to be less repeatable ${ }^{17}$ than $\mathrm{PD}_{20}$ and to add little information.

Most subjects (75\%) increased their $\mathrm{FEV}_{1}$ after the. post-saline measurement. In most the increase was $\vec{\omega}$ less than $100 \mathrm{ml}$, which is within the $200 \mathrm{ml} 95 \%$ rangeo that would be expected in subjects unfamiliar with a $\vec{x}$ spirometer. ${ }^{17}$ If we assume that the highest value is closer to the true $\mathrm{FEV}_{1}$ it is appropriate to take the? maximum $\mathrm{FEV}_{1}$ as a baseline rather than the post- $\overrightarrow{\mathrm{c}}$ saline $F E V_{1}$. This decision is supported by the slightlyo smaller intraclass correlation coefficient of the max-? imum $\mathrm{FEV}_{1}$ than of the post-saline $\mathrm{FEV}_{1}$ (table 3 ). $\overrightarrow{\mathrm{C}}$ The difference, however, between the results from the two methods is trivial, the $\mathrm{PD}_{20}$ derived from the maximum $\mathrm{FEV}_{1}$ being on average only $0.008 \log \mu$ mol (equivalent to 0.03 doubling doses) less than that $\vec{\omega}$ derived from the post-saline $\mathrm{FEV}_{1}$ (standard devi- $\underset{-}{ }$ ation of differences $0.036 \log \mu \mathrm{mol}$ ).

The repeatability of $\mathrm{PD}_{20}$ in this study, as estimated from curve 1, was similar to that found in laboratory based studies. Dehaut et $\mathbf{l}^{18}$ reported a $95 \%$ single determination "confidence interval" (strictly speaking $\frac{\mathrm{Q}}{\mathrm{O}}$ a range, not a confidence interval) of 1.59 doubling $\stackrel{\varrho}{\Rightarrow}$ concentrations; our within subject standard deviation of 0.27 gives a corresponding figure of 1.79 doubling 3 doses. When our calculation was restricted to data tested under conditions more like those that would be imposed in a laboratory setting the within subject standard deviation was $0 \cdot 18$, equivalent to a $95 \%$ 응 single determination interval of 1.2 doubling doses. Other laboratory studies have found better agreement $\frac{}{3}$ than Dehaut between duplicate measurements, in trained and selected subjects; but these results should 0 not be compared with our findings. An epidemio-

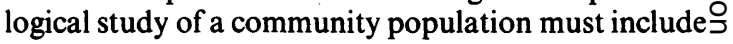
all respondents irrespective of technique if bias is to be $\frac{7}{0}$ avoided, and this will inevitably decrease repeatability of the method used.

Variability in FEV 1 makes linear interpolation from just two measurements unreliable and also은 reduces the number of estimates; the $\mathrm{FEV}_{1}$ at $4 \mu \mathrm{mol}^{\mathrm{\omega}}$ can, by chance, be greater than the previous value; this? renders linear extrapolation to a $\mathbf{P D}_{20}$ impossible whereas curve fitting will give an estimate. We did not $\$$ obtain a direct estimate of the short term repeatability? of $\mathrm{FEV}_{1}$, but the residual standard deviation about ${ }^{\circ}$ curve 1 was $0 \cdot 151$, well within the range of $0 \cdot 1-0 \cdot 31$ for different subgroups quoted by Tweeddale et al $^{18}$ for repeat $\mathrm{FEV}_{1}$ measurements in inexperienced subjects. $\stackrel{\odot}{\Omega}$ Extrapolation using curve 1 increased the number of 
$\mathrm{PD}_{20}$ values by about $20 \%$ without a reduction in repeatability (data available but not included). Extrapolation to one doubling dose beyond the maximum administered by fitting a curve to all the data is therefore justified and desirable in epidemiological surveys in which the maximum dose of histamine is low. In clinical studies, where larger doses can be given and where ease of computation may be important, interpolation between the last two points gives satisfactory results.

We would like to thank Mrs Renee Witts, Miss Marcia Kelson, Miss Karen Snowden, and Miss Leslie Neville for their assistance with the survey; Mr Frank Anderson and Mr Douglas Corfield for their help with testing lung function; Drs TE Roberts, P Harker, and D Law for helping to set up the study in the first instance; and Drs TE Wilson, D Davies, J Davies, D Pollard and R Lorge and the group practices in the areas for their cooperation with the study. We are greatly indebted to Mrs A Childs for preparing the manuscript. Finally we would like to thank the Department of Health and Social Security for financial support.

\section{Appendix: Fitting the curves}

Curve 1 is an exponential curve with a "slope" (b) and an upper asymptote (c) provided that $b$ is positive.

Curve 2 is a logistic (sigmoid) curve with an upper and a lower asymptote. The lower asymptote was fixed at zero $\mathrm{FEV}_{1}$ as doses of histamine were too low for $\mathrm{FEV}_{1}$ to reach the asymptote. (Woolcock et al, ${ }^{12}$ who gave higher doses, attempted to estimate the lower asymptote, but fixed the upper asymptote at the post-saline $\mathrm{FEV}_{1}$.)

Each curve was fitted iteratively by a two step procedure, with the post-saline $\mathrm{FEV}_{1}$ as the initial estimate of parameter $c$. Step 1 estimates $a$ and $b$. Given $a$ and $b$, step 2 estimates $c$ to give the minimum residual sum of squares on the FEV scale. Iteration was continued until there was a reduction in the residual sum of squares from the previous iteration and:

(i) $c$ changed by less than 0.01 ;

or

(ii) $c$ changed by less than 0.05 and number of iterations $>10$

or (iii) number of iterations $>50$.

CURVE $1 \quad y=c-\exp (a+b x)$

Step 1 Estimate $a$ and $b$ by regression of $\log _{\mathrm{e}}(c-y)$ on $x$. If some values of $\operatorname{FEV}_{1}(y)$ are greater than or equal to $c$, only data for values of $x$ greater than the highest $x$ for which $y>c$ are used.

Step 2 Estimate $c=(\Sigma \mathrm{y}+\Sigma \exp (a+b x)) / n$, where $n$ is total number of doses of histamine.

CURVE $2 y=c /(1+\exp (a+b x))$

Step 1 Estimate $a$ and $b$ by regression of $\log _{\mathrm{e}}((c-y) / y)$ on $x$. Omit data as for curve 1 .

Step 2 Estimate $c=\Sigma y z / z^{2}$, where $z=1 /(1+\exp (a$ $+b x))$.
Because minimisation in step 1 is on the log scale and that in step 2 on the original scale, non-convergence can occur. Omission of values in step 1 can also cause this, and the second and third criteria for stopping iteration were to cope with the few data sets for which this occurred. As rising curves were of no interest, $b$ was set to zero if a value less than zero resulted from step 1 .

Parameter $c$ is the asymptote of the curve unless $b$ is zero, when the "curve" is a straight line with ordinate $c-\mathrm{e}^{\mathrm{a}}$ for curve 1 or $c /\left(1+\mathrm{e}^{\mathrm{a}}\right)$ for curve 2 . The algorithms are approximate in that in some cases the minimum residual sum of squares will not be found-generally when the curve fits the data poorly. The computing time required for algorithms guaranteeing the best fit for each curve to each of the data sets, which totalled 897 , could not be justified. The algorithms failed to converge for less than $5 \%$ of data sets.

The program to fit the curves was written in FORTRAN for a minicomputer. The calculations for fitting curve 1 could be carried out on a microcomputer, or even on a sophisticated programmable calculator provided that sufficient data stores as well as program steps are available.

\section{References}

1 Boushey HA, Holtzman MJ, Sheller JR, Nadel JA. State of the art bronchial hyperreactivity. Am Rev Respiratory Dis 1980;121:389-411.

2 Laitinen LAI. Histamine and metacholine challenge in the testing of bronchial reactivity. Scand J Respir Dis 1974;suppl 86.

3 Juniper EF, Frith PA, Hargreave FE. Airway responsiveness to histamine and metacholine: relationship to minimum treatment to control symptoms of asthma. Thorax 1981;36:575-9.

4 Ryan G, Latimer KM, Dolovitch J, Hargreave FE. Bronchial responsiveness to histamine: relationship to diurnal variation of peak flow rate, improvement after bronchodilator, and airway calibre. Thorax 1982;37:423-9.

5 Eiser NM, Kerrebijn KF, Quanjer PH. Guidelines for standardisation of bronchial challenges with (non-specific) bronchoconstricting agents. Bull Eur Physiopathol Respir 1983;19:495-514.

6 Yan K, Salome C, Woolcock AJ. Rapid method for measurement of bronchial responsiveness. Thorax 1983;38:760-5.

7 Britton JR, Mortagy A, Tattersfield AF. Histamine challenge testing: comparison of three methods. Thorax 1986;41:128-32.

8 Burney PGJ, Britton JR, Chinn S, et al. The descriptive epidemiology of bronchial reactivity in an adult population: results from a community study. Thorax 1987;42:38-44.

9 Cotes JE. Lung function: assessment and measurement. 4th ed. Oxford: Blackwell Scientific Publications, 1979:369.

10 Juniper EF, Frith PA, Dunnett C, Cockcroft DW, Hargreave FE. Reproducibility and comparison of responses to inhaled histamine and metacholine. Thorax 1978;33:705-10.

11 Cockcroft DW, Ruffin RE, Dolovich J, Hargreave FE. 
Allergen-induced increase in non-allergic bronchial reactivity. Clin Allergy 1977;7:503-13.

12 Woolcock AJ, Salome CM, Yan K. The shape of the dose-response curve to histamine in asthmatic and normal subjects. Am Rev Respir Dis 1984;130:71-5.

13 Altman DG, Bland JM. Measurement in medicine: the analysis of method comparison studies. Statistician 1983;32:307-17.

14 Fisher RA. Statistical methods for research workers. 14th ed. Edinburgh: Oliver and Boyd, 1970:225.

15 Neijens HJ, Hofkamp M, Degenhart HJ, Kerrebijn KF. Bronchial responsiveness as a function of inhaled histamine and the methods of measurement. Bull Eur
Physiopathol Respir 1982;18:427-38.
16 Cockcroft DW, Berscheid BS, Murdock KY. Meas surement of responsiveness to inhaled histamine using $\mathrm{FEV}_{1}$ : comparison of $\mathrm{PC}_{20}$ and threshold. Thora. 1983;38:523-6.

17 Tweeddale PM, Merchant S, Leslie M, Alexander F McHardy GJR. Short term variability in FEV $_{1} \varrho$ relation to pretest activity, level of $F E V_{1}$, and smokings habits. Thorax 1984;39:928-32.

18 Dehaut P, Rachiell A, Martin RR, Malo JL. Histamine dose-response curves in asthma: reproducibility an sensitivity of different indices to assess response. Thoo $\operatorname{rax} 1983 ; 38: 516-22$. 